\title{
Ankara Koşullarında Bazı Yemlik Pancar (Beta vulgaris L. ssp. crassa Mansf.) Çeşitlerinin Verim ve Verim Öğeleri Bakımından Karşılaştırılması
}

\author{
Altıngül ÖZASLAN PARLAK ${ }^{1} \quad$ Hayrettin EKIZ $^{2}$
}

Geliş Tarihi: 23.07.2007

Kabul Tarihi: 06.05.2008

\begin{abstract}
Öz: Bu çalışmada Rota, Eckdorot, Eckdogella, Hat1 ve Hat2 yemlik pancar çeşitlerinin bitki boyu, kökgövde boyu, kök-gövde çapı, yaş yaprak ağırlığı, yaş yaprak verimi, yaş kök-gövde ağırlığı, kök-gövde kuru madde oranı ve kök-gövde kuru madde verimi incelenerek en verimli çeşidin belirlenmesi amaçlanmıştır. Araştırma Ankara Üniversitesi Ziraat Fakültesi Tarla Bitkileri Bölümü deneme tarlasında 2003-2004 yıllarında tesadüf blokları deneme desenine göre üç tekrarlamalı olarak yürütülmüştür. Ekim ilk yıl 1nisan, ikinci yıl 5 nisan, hasat ilk yıl 2 ekim, ikinci yıl 7 ekim tarihlerinde yapılmıştır. Denemede kullanılan tüm çeşitlerin iki yılın ortalaması olarak bitki boyu $40.80 \mathrm{~cm}$, kök-gövde boyu $19,94 \mathrm{~cm}$, kök-gövde çapı $10.74 \mathrm{~cm}$, yaş yaprak ağırlığı $0.185 \mathrm{~kg} / \mathrm{bitki}$, yaş yaprak verimi $1937.99 \mathrm{~kg} / \mathrm{da}$, yaş kök-gövde ağırlığı $1.015 \mathrm{~kg} / \mathrm{bitki}$, kök-gövde kuru madde oranı (\%) 16,10 ve kök-gövde kuru madde $817.68 \mathrm{~kg} / \mathrm{da}$ olarak belirlenmiş ve incelenen bu özellikler arasında önemli bir fark bulunmamıştır. Yalnızca yaş kök-gövde verimi arasında fark tespit edilmiştir. En yüksek kök gövde verimi Eckdorot çeşidinde $(5886.67 \mathrm{~kg} / \mathrm{da})$ belirlenmiştir. Fakat kök-gövde kuru madde verimi arasında fark çıkmadığı için bütün çeşitler Ankara ve benzer koşullarda yetiştirilebilir.
\end{abstract}

Anahtar Kelimeler:Yemlik pancar, verim öğeleri, yumru verimi

\section{The Comparison of Yield and Yield Components in Some Fodder Beet (Beta vulgaris L. ssp. crassa Mansf.) Varieties under Ankara Conditions}

\begin{abstract}
This study was performed in fodder beet varieties (Rota, Eckdorot, Eckdogella, Line1 and Line2) to determine the highest yielding variety using the characteristics; plant length, root length, root diameter, leaf weight, leaf yield, root weight, root dry matter content and root dry matter related with yield. The research was carried out at the experimental field of Department of Field Crops, Faculty of Agriculture and Ankara University in 2003-2004 and the experimental design was a randomized complete block with three replications. Sowing dates were April 1 and 2 in 2003 and 2004, respectively. The plants were harvested on October 2 and 7 in two consequent years. Two year mean values were $40.80 \mathrm{~cm}$ in plant length, $19.94 \mathrm{~cm}$ root length, $10.74 \mathrm{~cm}$ root diameter, $0.185 \mathrm{~kg}_{\text {plant }}{ }^{-1}$ leaf weight, $1937.99 \mathrm{~kg} \mathrm{da}^{-1}$ leaf yield, $1.015 \mathrm{~kg} \mathrm{plant}^{-1}$ root weight, 16.10 root dry matter content (\%) and $817.68 \mathrm{~kg} \mathrm{da}^{-1}$ root dry matter yield. No statistically important differences were found in these characteristics, except for root yield. The highest root yield was obtained from Eckdorot variety. All the varieties can be cultivated in Ankara and under the same ecological conditions due to the fact that the varieties showed no differences in terms of root matter yield.
\end{abstract}

Key Words: Fodder beet, yield components, root yield

\section{Giriş}

Ülkemizde önemli kaba yem kaynaklarından olan meralar uzun yıllardır devam eden erken ve ağır otlatmadan dolayı verimleri azalmıştır. Orta Anadolu'da buna bir de kuraklık eklenince çoğu meralar bitk örtülerini kaybetmesinin yanında verimli toprak tabakasını da kaybetmektedirler. Aşırı derecede erozyona uğramış meralarda iyileştirme çalışmaları da başarısızlıkla sonuçlanmaktadır. 4342 sayılı mera kanunu bünyesinde yapılan mera ıslah çalışmalarının başarıya ulaşması ve devamlıığının yanında, hayvancılık işletmelerinin karlılığının artırılmasında tarla tarımı içerisinde yem bitkileri yetiştiriciliğine yer verilmesi de kaçınılmazdır.

Orta Anadolu'da ekim alanı kota uygulamalarından dolayı şeker pancarı üretiminde azalma meydana gelmiştir. Yemlik pancar morfolojik.

${ }^{1}$ Çanakkale Onsekiz Mart Üniv. Ziraat Fak. Tarla Bitkileri Bölümü-Çanakkale

${ }^{2}$ Ankara Üniv. Ziraat Fak. Tarla Bitkileri Bölümü-Ankara 
özellikleri bakımından şeker pancarından biraz farklıdır, fakat yetiştiricilik açısından benzerdir. Bu nedenle yöre çiftçisi tarafından benimsenip ekilmesi daha kolay olacaktır

Yemlik pancar meraların kuruduğu veya üretimin yetersiz olduğu dönemlerde bol ve kaliteli yeşil ot ile kök ürünü verebilen, özellikle sulu koşullarda çok verimli bir bitkidir. Moloney ve O'Kiely (1999) yemlik pancarın uygun şartlarda yetiştirildiğinde buğdaygil yem bitkilerinden daha verimli olduğunu belirtmişlerdir. Yemlik pancar dekara $2000 \mathrm{~kg}$ kuru madde üretirken, dört hasat sonucunda buğdaygillerin dekara 13001500 kg kuru madde ürettiğini bildirmişlerdir. Özen ve ark. (1981), yemlik pancarın hava şartları elverişl olduğu sürece, toprakta bırakılarak sökülüp taze taze yedirilebileceğini, bunun yanında su düzeyinin fazlalığ (\%87) ve şeker pancarında olduğu gibi kuru maddesinin \%70'e yakın kısmını şekerlerin oluşturmasından dolayı laktasif etkiye sahip olup, özellikle süt inekleri için çok uygun yem olduğunu, Avrupa ülkelerinde sığır besiciliğinde doğranıp yedirilebildiği gibi saman ve doğranmış otlarla karıştırılarak yedirildiğini de belirtmişlerdir. Bunlara ilaveten silaj yapımında da kullanılmaktadır. Skultely ve ark. (1991) yemlik pancara \%20 oranında mısır koçan kavuzları ya da \%10 oranında arpa saman katılarak yapılan silajın kalitesi ve besleme değerinin oldukça iyi olduğunu belirtmişlerdir. Birkenmaier ve ark. (1996)'da farklı miktarlarda yemlik pancar ile inekleri beslemiştir. Yemlik pancar miktarının artırılmasıyla süt veriminin düştüğünü, fakat sütteki yağ oranının arttığını belirtmişlerdir. Yemlik pancar ve buğdaygillerden oluşturulan silajla birlikte beslemenin girdi masraflarını azalttığını bildirmişlerdir.

Krousky (1991) tarafından yapılan çalışmada yemlik pancarın ekim zamanının 14 gün gecikmesiyle sulanmayan alanlarda \%55,6 oranında, sulanan alanlarda ise \%36 oranında verimde kayıplar olduğunu bildirmiştir. İzmir ekolojik koşullarında yapılan çalışmada da ekim zamanı geciktikçe ve bitki sıklığı azaldıkça verimde düşme eğilimi görülmüştür (Avcıoğlu ve ark. 1999). Nadaf ve ark. (1998) tarafından Umman'da yapılan çalışmada yemlik pancarın Peramono, Petra ve Anissa çeşitleri kullanılmıştır. Bu çeşitler arasında verim, besleme değeri ve kalitesi bakımından önemli fark bulunmamıştır. Çeşitlerin ortalama verimi ilk yıl 9462 11088 kg/da olurken ikinci yıl 13641 - 15108 kg/da olarak belirlenmiştir. Acar, (2000) Konya'da yemlik pancarın Rota, Petra çeşitleri ve M229 hattın kullanarak farklı ekim zamanı ve bitki sıklıklarını incelemiştir. En yüksek verim 5 nisan tarihinde dekara 8500 bitki sıklığında ekim yapılan Petra çeşidinde bulmuştur. Yaş kök-gövde verimi $14515.8 \mathrm{~kg} / \mathrm{da}$ ve kök-gövde kuru madde verimi 1741.2 kg/da olduğunu belirtmiştir. Afyon Mandacılık Araştırma Enstitüsünde yürütülen denemede Rota çeşidinin $2342.75 \mathrm{~kg} / \mathrm{da}$ yaprak, $9093.75 \mathrm{~kg} / \mathrm{da}$ kök-gövde verimi aldıklarını bildirmişlerdir (Çetin ve Özhan 1992).

$\mathrm{Bu}$ araştırmada yemlik pancarın verim ve verimle ilgili bazı özellikleri ele alınmış, materyal olarak ele alınan çeşitler içerisinde karşılaştırma yapılmış ve en önemli çeşidin belirlenmesi yoluna gidilmiştir.

\section{Materyal ve Yöntem}

Bu araştırma 2003 - 2004 vejetasyon yıllarında Ankara Üniversitesi Ziraat Fakültesi Tarla Bitkileri Bölümü deneme tarlasında, iki farklı arazide yürütülmüştür. Araştırmanın ilk yılında denemenin toprakları killi tın bünyeli, $\mathrm{pH}=7.37$, organik madde $\% 1.37, \% \mathrm{CaCO}_{3} 5.35$, alınabilir $\mathrm{P}$ ve $\mathrm{K}$ sırasıyla 4.35 $\mathrm{kg} / \mathrm{da}, 130 \mathrm{~kg} / \mathrm{da}$ dır. Denemenin ikinci yılındaki arazinin toprakları aynı bünyede, $\mathrm{pH}=7.85$, organik madde $\% 1.33, \% \mathrm{CaCO}_{3} 6.0$, alınabilir $\mathrm{P}$ ve $\mathrm{K}$ sırasıyla 5.02 kg/da, 144 kg/da'dır. Araştırma yerinin yetiştirme dönemindeki iklim verileri Çizelge 1'de gösterilmiştir.

Araştırmada materyal olarak, yemlik pancar (Beta vulgaris L. ssp. crassa Mansf.)'ının Atakol tohumculuktan temin edilen Rota, Eckdorot ve Eckdogelb çeşitleri ile Kocatepe Tarımsal Araştırma Enstitüsü'nün iki adet sentetik hattı (Hat1, Hat2) kullanılmıştır. Rota çeşidi multigerm yapıda olup, kitle pancarı grubuna girmektedir. Eckdorot ve Eckdogelb çeşitleri diploid multigerm çeşitlerdir. Eckdorot kırmızı gövdeli, Eckdogelb sarı gövdelidir. Sentetik hatlardan olan Hat1 kırmızı gövdeli, Hat2 ise sarı gövdelidir.

Deneme, tesadüf blokları deneme desenine göre 3 tekerrürlü olarak kurulmuştur. İlk yıl ekim 1 Nisan, ikinci yıl ise 5 Nisan tarihlerinde, hasat ise 2003 yılında 2 Ekim, 2004 yılında 7 Ekim tarihlerinde yapılmıştır. Her çeşit 10 sıra olacak şekilde $45 \mathrm{~cm}$ sıra aralığı, 30 $\mathrm{cm}$ sıra üzeri bırakılarak $5 \mathrm{~m}$ uzunluğunda sıralara elle ekim yapılmıştır. Denemede parsel büyüklüğü $5 \mathrm{~m} \mathrm{x}$ $4.5 \mathrm{~m}=22.5 \mathrm{~m}^{2}$ olmuştur. Dekara $1 \mathrm{~kg}$ tohum atılmıştır. 19-20 nisan tarihlerinde fide çıkışı olmuş ve çıkış tamamlandıktan sonra seyreltme işlemine gidilmiştir. Yabancı ot mücadelesi 5-9 mayıs tarihinde elle yapılmıştır. Ekimle birlikte dekara $5 \mathrm{~kg} \mathrm{~N}, 15 \mathrm{~kg}$ $\mathrm{P}_{2} \mathrm{O}_{5}$ gübresi verilmiş. Illk çapalamada ise $5 \mathrm{~kg} / \mathrm{da} \mathrm{N}$ verilerek dekara toplam $10 \mathrm{~kg} \mathrm{~N}$ uygulanmıştır.

Yemlik pancarının özelliklerini belirlemek için ölçümler hasat sırasında her parselden tesadüfen alınan 10 bitki üzerinde yapılmış ve ortalamaları alınmıştır. Hasat her iki yılda da eylül ayının sonunda yapılmıştır. Bitki boyu, hasattan önce toprak yüzeyi üzerinden bitkilerin boyları ölçülmüştür. Hasattan hemen sonra kök-gövde uzunluğu cetvelle ölçülmüş, kök-gövdenin en geniş olduğu kısımdan da kumpas 
yardımıyla kök-gövde çapı belirlenmiştir. Hasat edilen bitkilerin yaprakları kökten ayırdıktan sonra hemen tartılarak yaş yaprak ağırığı kökleri tartılarak, yaş kökgövde ağırlığı belirlenmiştir. Tüm parsel her iki taraftan bir sıra ve $50 \mathrm{~cm}$ kenar tesiri bırakılarak elle hasat edilmiş ve kökten yaprakları ayrıldıktan sonra tartılarak yaş yaprak verimi ve yaş kök-gövde verim saptanmıştır. Daha sonra parsel verimleri dekara çevrilmiştir. Köklerden $50 \mathrm{~g}$ lık yaş örnekler alınarak $105{ }^{\circ} \mathrm{C}$ etüvde 24 saat kurutulduktan sonra tartılarak kök-gövde kuru madde oranı belirlenmiştir. Kök-gövde kuru madde oranı kök-gövde verimi ile çarpılarak dekara kuru madde verimi belirlenmiştir.

Araştırmada elde edilen veriler tesadüf blokları deneme desenine göre MSTAT-C bilgisayar programında varyans analizine tabi tutulmuş Ortalamalar LSD (\%5)'ye göre gruplandırılmıştır (Düzgüneş ve ark.1987).

\section{Bulgular ve Tartışma}

Bitki boyu: Her iki deneme yılında da (2003 2004) hayvan pancarının bitki boyu karakterinde çeşitler arasında önemli bir fark bulunmamıştır. Yemlik pancarın beş çeşidinde de bitki boyu birbirine yakın olmuştur. 2003 yılında Eckdorot çeşidinin bitki boyu $41.13 \mathrm{~cm}$ ile en fazla olurken bunu $40.00 \mathrm{~cm}$ ile Rota ve Eckdogella çeşitleri takip etmiştir. Hat1 ve Hat2' nin bitki boyuda sırasıyla 39.40, $39.73 \mathrm{~cm}$ olmuş ve aralarındaki bu çok küçük fark önemsiz olmuştur. 2004 yılında da benzer sonuçlar elde edilmiştir. Rota, Eckdorot, Eckdogella, Hat2 ve Hat2' nin bitki boylar sırasıyla 40.13, 43.13, 42.00, 40.73, $41.73 \mathrm{~cm}$ olarak ölçülmüştür (Çizelge 2).

Kök-gövde boyu: Yemlik pancarın beş çeşidinin de kök-gövde boyları birbirine yakın değerlerde yer almasından dolayı 2003 ve 2004 yıllarında ve her iki yılın ortalamasında istatistikî olarak önemsiz çıkmıştır. İlk yıl Hat2 çeşidinin kök-gövde boyu $21.60 \mathrm{~cm}$ olurken bunu $19.07 \mathrm{~cm}$ ile Hat1 takip etmiştir. Eckdogella çeşidi $18.60 \mathrm{~cm}$, Rota çeşidi $17.20 \mathrm{~cm}$, Eckdorot çeşidi de $16.40 \mathrm{~cm}$ olmuş fakat aralarındaki bu farkın çok az olmasından dolayı istatistiki bir fark yaratmamıştır. İkinci yılda da kök-gövde boyları ilk yıla göre biraz uzun olmuştur. Yine çeşitler arasında farklılık olmamıştır. İlk yıl olduğu gibi en uzundan en kısaya doğru çeşitler Hat2, Eckdogella, Rota, Eckdorot ve Hat1 şeklinde sıralanmıştır.

Kök-gövde çapı: Çeşitlerin kök-gövde çaplarında da deneme yıllarında ve yılların ortalamasında farklılıklar önemsiz olmuştur. Rota çeşidinin kök-gövde çapı ilk yıl $9.72 \mathrm{~cm}$, ikinci yıl 10.68 $\mathrm{cm}$, Eckdorot çeşidinin ise ilk yıl $9.34 \mathrm{~cm}$, ikinci yıl $11.23 \mathrm{~cm}$, Eckdogella' nın ise ilk yıl ve ikinci yıl sırasıyla 10.59, $10.98 \mathrm{~cm}$, Hat1 ve Hat2 çeşitlerinin sırasıyla ilk yıl 10.10, $11.53 \mathrm{~cm}$, ikinci yıl 11.30, 11.89 cm olarak ölçülmüştür.

Ülkemizde yapılan çalışmaların çoğunda yemlik pancarın Rota çeşidi yaygın olarak kullanılmıştır. Denemede kullanılan beş çeşidin bitki boyu, kök-gövde boyu ve kök-gövde çapı arasında önemli bir fark ortaya çıkmamıştır. Albayrak ve Çamaş (2005) Çarşamba ve Bafra ovasında Ecdogelb ve Ecdorot çeşitleriyle yaptığı araştırmada her iki çeşidin kök-gövde boyu ve çapı arasında fark olmadığını saptamıştır. Geren ve Avcıoğlu (1997)'nun İzmir'de yaptığı çalışmada Rota çeşidinde bitki boyunu ortalama $35.9 \mathrm{~cm}$ olarak belirlemiştir. Elmalı (1998) adlı araştırıcı da yine aynı çeşit ve aynı bölgede yaptığı çalışmada bitki boyunu ortalama $40.8 \mathrm{~cm}$, kök-gövde uzunluğunu $13.0 \mathrm{~cm}$, kök-gövde çapını $10.7 \mathrm{~cm}$ olarak ölçmüştür. Harran ovasında yine Rota çeşidi ile yapılan çalışmada Açanal (1999) tüm uygulamaların ortalaması kök-gövde uzunluğunu $12.2 \mathrm{~cm}$, kök-gövde çapını da $9.8 \mathrm{~cm}$ olarak belirlemiştir. Araştırmacıların sonuçları özellikle bitki boyu sonuçlarımız ile benzerlik göstermektedir. Acar (2000) adlı araştırıcı Konya'da yine Rota çeşidiyle yaptığı çalışmada ortalama bitki boyunu $53.59 \mathrm{~cm}$ belirleyerek yetiştirdiğimiz aynı çeşitten daha uzun bitki boyu ölçmüştür. Bitki boyundaki bu farklılık çeşit $x$ çevre interaksiyonundan kaynaklanmış olabilir.

Çizelge 1. Araştırma yerinin iklim verileri

\begin{tabular}{|l|c|c|c|c|c|c|c|c|c|}
\hline \multirow{2}{*}{ Aylar } & \multicolumn{3}{|c|}{ Aylık toplam yağış $(\mathrm{mm})$} & \multicolumn{3}{c|}{ Aylık ortalama sıcaklık $\left({ }^{\circ} \mathrm{C}\right)$} & \multicolumn{3}{c|}{ Aylık ortalama nispi nem (\%) } \\
\cline { 2 - 11 } & $\begin{array}{c}\text { Uzun } \\
\text { yıllar }\end{array}$ & 2003 & 2004 & $\begin{array}{c}\text { Uzun } \\
\text { yllar }\end{array}$ & 2003 & 2004 & $\begin{array}{c}\text { Uzun } \\
\text { yıllar }\end{array}$ & 2003 & 2004 \\
\hline Nisan & 43.9 & 70.3 & 38.0 & 11.1 & 10.3 & 11.5 & 59 & 62.4 & 55.0 \\
\hline Mayıs & 52.0 & 18.0 & 33.8 & 15.8 & 19.0 & 15.8 & 58 & 52.9 & 57.2 \\
\hline Haziran & 34.2 & - & 25.6 & 19.8 & 22.6 & 20.0 & 52 & 46.6 & 57.4 \\
\hline Temmuz & 15.1 & 3.0 & 6.2 & 23.2 & 23.5 & 23.6 & 45 & 49.5 & 49.0 \\
\hline Ağustos & 11.3 & 0.2 & 12.6 & 23.0 & 24.3 & 22.9 & 44 & 48.1 & 54.3 \\
\hline Eylül & 17.3 & 15.1 & 2.7 & 18.5 & 18.0 & 19.3 & 48 & 58.9 & 49.7 \\
\hline Ortalama & - & - & - & 18.57 & 19.62 & 18.85 & 51.0 & 53.07 & 53.77 \\
\hline Toplam & 173.8 & 106.6 & 118.9 & - & - & - & - & - & - \\
\hline
\end{tabular}


Çizelge 2. Yemlik pancar çeşitlerinin 2003, 2004 ve iki yılın ortalamasında bazı verim özellikleri

\begin{tabular}{|c|c|c|c|c|c|c|c|c|c|}
\hline Çeşitler & $\begin{array}{l}\text { Bitki boyu } \\
(\mathrm{cm})\end{array}$ & $\begin{array}{l}\text { Kök- } \\
\text { gövde } \\
\text { boyu } \\
(\mathrm{cm})\end{array}$ & $\begin{array}{l}\text { Kök- } \\
\text { gövde } \\
\text { çapı } \\
\text { (cm) }\end{array}$ & $\begin{array}{c}\text { Bitkide } \\
\text { yaş } \\
\text { yaprak } \\
\text { ağırlığı } \\
\text { (kg/bitki) }\end{array}$ & $\begin{array}{c}\text { Dekara } \\
\text { yaş } \\
\text { yaprak } \\
\text { verimi } \\
(\mathrm{kg} / \mathrm{da})\end{array}$ & $\begin{array}{c}\text { Bitkide } \\
\text { yaş kök- } \\
\text { gövde } \\
\text { ağırlığı } \\
\text { (kg/bitki) }\end{array}$ & $\begin{array}{c}\text { Dekara } \\
\text { yaş kök- } \\
\text { gövde } \\
\text { verimi } \\
\text { (kg/da) }\end{array}$ & $\begin{array}{c}\text { Kök- } \\
\text { gövde } \\
\text { kuru } \\
\text { madde } \\
\text { oranı } \\
(\%)\end{array}$ & $\begin{array}{c}\text { Kök- } \\
\text { gövde } \\
\text { kuru } \\
\text { madde } \\
\text { verimi } \\
\text { (kg/da) }\end{array}$ \\
\hline
\end{tabular}

\begin{tabular}{|c|c|c|c|c|c|c|c|c|c|c|}
\hline \multicolumn{11}{|c|}{2003 Yılı } \\
\hline Rota & 40.00 & 17.20 & 9.72 & 0.149 & 1336.00 & 0.693 & 5737.67 & & 15.57 & 896.77 \\
\hline Eckdorot & 41.13 & 16.40 & 9.34 & 0.143 & 1470.00 & 0.644 & 5244.67 & & 16.23 & 850.77 \\
\hline Eckdogella & 40.00 & 18.60 & 10.59 & 0.176 & 1328.00 & 0.917 & 5421.67 & & 15.63 & 849.70 \\
\hline Hat1 & 39.40 & 19.07 & 10.10 & 0.179 & 1794.33 & 0.779 & 5380.67 & & 18.03 & 975.20 \\
\hline Hat2 & 39.73 & 21.60 & 11.53 & 0.160 & 1644.33 & 1.296 & 4820.33 & & 16.27 & 774.63 \\
\hline Ortalama & 40.05 & 18.57 & 10.26 & 0.161 & 1514.53 & 865.99 & 5321.00 & & 16.35 & 869.41 \\
\hline \multicolumn{11}{|c|}{2004 Yilı } \\
\hline Rota & 40.13 & 21.23 & 10.68 & 0.183 & 2443.67 & 1.058 & 4750.67 & $b c^{*}$ & 15.17 & 717.85 \\
\hline Eckdorot & 43.13 & 20.53 & 11.23 & 0.185 & 2436.33 & 1.028 & 6528.67 & a & 15.14 & 986.83 \\
\hline Eckdogella & 42.00 & 21.93 & 10.98 & 0.209 & 2792.67 & 1.250 & 5266.67 & $a b$ & 15.14 & 801.44 \\
\hline Hat1 & 40.73 & 20.37 & 11.30 & 0.202 & 2252.67 & 1.026 & 4337.00 & bc & 16.48 & 728.81 \\
\hline Hat2 & 41.73 & 22.43 & 11.89 & 0.261 & 1881.67 & 1.467 & 3433.00 & $\mathrm{C}$ & 17.34 & 594.79 \\
\hline Ortalama & 41.55 & 21.30 & 11.22 & 0.208 & 2361.40 & 1.166 & 4863.20 & & 15.85 & 765.94 \\
\hline \multicolumn{11}{|c|}{ İki Yılın Ortalaması } \\
\hline Rota & 40.07 & 19.22 & 10.20 & 0.166 & 1889.97 & 0.876 & 4910.83 & $b$ & 15.37 & 807.30 \\
\hline Eckdorot & 42.13 & 18.47 & 10.29 & 0.164 & 1953.17 & 0.836 & 5886.67 & $a$ & 15.69 & 918.80 \\
\hline Eckdogella & 41.00 & 20.28 & 10.79 & 0.193 & 2060.33 & 1.083 & 5344.17 & $a b$ & 15.39 & 825.56 \\
\hline Hat1 & 40.07 & 19.72 & 10.71 & 0.190 & 2023.50 & 0.903 & 4858.83 & $b$ & 17.25 & 852.00 \\
\hline Hat2 & 40.73 & 22.02 & 11.71 & 0.210 & 1763.00 & 1.382 & 3960.00 & C & 16.80 & 684.72 \\
\hline Ortalama & 40.80 & 19.94 & 10.74 & 0.185 & 1937.99 & 1.015 & 4992.10 & & 16.10 & 817.68 \\
\hline
\end{tabular}

* Farklı harflerle gösterilen çeşit ortalamaları arasındaki farklar istatistiksel olarak önemlidir.

Bitkide yaş yaprak ağırlığı: Yaş yaprak ağırlığı hasat edilen 10 tane yemlik pancar yaprakları köklerinden ayrıldıktan hemen sonra tartılıp ortalamaları alınarak yapılmıştır. Yemlik pancar çeşitlerinin morfolojik özelliklerinde olduğu gibi yaş yaprak ağırlığında da istatistiki olarak fark çıkmamıştır. Bitki başına yaş yaprak ağırlığı 2003 yılında Rota, Eckdorot, Eckdogella, Hat1 ve Hat2 çeşitlerinde sırasıyla $0.149,0.143,0.176,0.179$ ve $0.160 \mathrm{~kg} / \mathrm{bitki}$ olarak belirlenirken, 2004 yılında yine aynı sırayla $0.183,0.185,0.209,0.202$ ve $0.261 \mathrm{~kg} / \mathrm{bitki}$ olarak belirlenmiştir. 2003 yılında tüm çeşitlerin ortalaması olarak yaş yaprak ağırlığı 0.161 kg/bitki olurken 2004 yılında $0.208 \mathrm{~kg} / \mathrm{bitki}$ olarak belirlenmiştir.

Dekara yaş yaprak verimi: Yaş yaprak ağırlığında çeşitler arasında fark çıkmadığından dolayı yaş yaprak veriminde de istatistiki olarak fark olmamıştır. Denemenin ilk yılı yaş yaprak verimi Rota çeşidinin 1336.00 kg/da, Eckdorot' nın 1470.00 kg/da, Eckdogella' nın $1328.00 \mathrm{~kg} / \mathrm{da}$, Hat1 ve Hat2'nin sırasıyla $1794.33,1644.33 \mathrm{~kg} /$ da olarak belirlenmiştir. İkinci yılda ise en yüksek yaş yaprak verimi sırasıyla Eckdogella, Rota, Eckdorot, Hat1 ve Hat2 çeşitlerinde alınmış, fakat aralarındaki fark birbirine yakın olmasından dolayı istatistiki olarak farklılık çıkmamıştır. Denemenin ilk ve ikinci yıllarında yaş yaprak verimi ortalama sırasıyla 1514.53, $2361.40 \mathrm{~kg} / \mathrm{da}$ olarak hesaplanmıştır.

Yaş yaprak ağırlığı bütün çeşitlerde birbirine yakın olmasından dolayı tüm parsel hasat edilerek bulunan yaş yaprak verimlerinde de istatistikî olarak farklılık ortaya çıkmamıştır. 2003 yılında hem yaş yaprak ağırlığı, hem de dekara yaprak verimi 2004 yılına göre daha az olmuştur. İkinci yıl ilk yıla göre yağış daha fazla olmuş, buna karşılık sıcaklıkta daha düşük seyretmiştir. Bu durumda sıcaklığın düşük yağışın fazla olması topraktaki nemin daha uzun kalmasına neden olduğu için ikinci yıl yaş yaprak ağırlığı da verimi de daha yüksek olmuştur. İzmir ekolojik şartlarında Geren ve Avcıoğlu (1997) Rota 
çeşidinin yaprak verimini $2483 \mathrm{~kg} / \mathrm{da}$, Sağlamtimur ve Tansı (1989) adlı araştırıcılarda Çukurova şartlarında yine Rota çeşidinde $1559.83 \mathrm{~kg} / \mathrm{da}$ yaprak verimi, Samsun ekolojik şartlarında ise Ecdo gelb ve Ecdorot çeşitlerinde iki yıllık ortalama yaprak verimi sırasıyla 1190, 1230 kg/da olarak belirlemişlerdir. Yapılan bu çalışmalarda yaprak verimi bakımından benzerlik göstermektedir. Yaprak verimi bakımından farklılık olan çalışmalar ise Afyon'da yapılan çalışmada ise Rota çeşidinde $2342.75 \mathrm{~kg} / \mathrm{da}$ yaprak verimi alınmıştır (Çetin ve Özkan 1992). Lee ve ark. (1995) Kore'de yaptıklar çalışmada ortalama yaprak verimini $2021 \mathrm{~kg} / \mathrm{da}$ bulmuşlardır. Açanal (1999) Haran ovasında ortalama yaprak verimini $473 \mathrm{~kg} / \mathrm{da}$ olarak belirlemiştir.

Bitkide yaş kök-gövde ağırlığı: Deneme yıllarında yemlik pancar çeşitleri arasında yaş kökgövde ağırlığı bakımından fark çıkmamıştır. Rota çeşidinin yaş kök ağırlığı ilk yıl 0.693 kg/bitki olurken, ikinci yıl 1.058 kg/bitki olmuştur. Eckdorot, Eckdogella, Hat1 ve Hat2 çeşitlerinde yaş kök ağırlığı ilk yıl ve ikinci yıl sırasıyla $0.644-1.028,0.917-1.250,0.779$ - 1.026, 1.296 - 1.467 kg/bitki olarak belirlenmiştir. Doğal olarak her iki yılın ortalamasında da farklılık çıkmamıştır. Yaş kök gövde ağırlığı denemenin ilk yılında ortalama $865.99 \mathrm{~kg} / \mathrm{bitki}$ olurken, denemenin ikinci yılında ortalama $1.166 \mathrm{~kg} / \mathrm{bitki}$ olarak belirlenmiştir.

Dekara yaş kök-gövde verimi: Yapılan çalışmada yemlik pancar çeşitleri arasında ilk yıl farklılık çıkmazken ikinci yıl önemli farklıık ortaya çıkmıştır. İkinci yılda en yüksek yaş kök verimi 6528.67 $\mathrm{kg} / \mathrm{da}$ ile Eckdorot çeşidinden elde edilmiştir. Bunu $5266.67 \mathrm{~kg} / \mathrm{da}$ ile Eckdogella, $4750.67 \mathrm{~kg} / \mathrm{da}$ ile Rota izlemiştir. Rota çeşidi ile Hat1 $(4337.00 \mathrm{~kg} / \mathrm{da})$ çeşidi aynı istatistiki grupta yer almıştır. En düşük verim $3433.00 \mathrm{~kg} / \mathrm{da}$ ile Hat2 çeşidinde belirlenmiştir. Her ik yılın ortalamasına baktığımızda da önemlilik görülmüştür. Burada da ikinci yılda olduğu gibi verim; Eckdorot $>$ Eckdogella $>$ Rota $=$ Hat $1>$ Hat2 şeklinde sıralanmıştır. Yaş kök-gövde verimi 2003 yılında ortalama $5321.00 \mathrm{~kg} / \mathrm{da}$ olarak alınırken, 2004 yılında ortalama $4863.20 \mathrm{~kg} / \mathrm{da}$ olarak alınmıştır. 2004 yılında Hat1 ve Hat2 çeşitlerinde homojen olmayan kök-gövde gelişmesi belirlenmiştir. $\mathrm{Bu}$ çeşitlerin bulunduğu parsellerde 10 bitki tesadüf olarak alınmıştır, fakat tüm parsel hasat edildiğinde çok az büyüyen köklerin olması ikinci yılda ortalama verimin azalmasına neden olmuştur.

Kök-gövde kuru madde oranı ve verimi: İncelenen her iki özellikte çalışma yıllarında çeşitler arasında farkılık ortaya çıkmamıştır. Tüm çeşitlerde kuru madde oranı ilk yıl \%16.35, ikinci yıl \%15.85; her iki yılın ortalamasında \%16.10 olarak belirlenmiştir. Kök kuru madde verimi, yaş kök verimi ile kök kuru madde oranının çarpılmasından elde edilmiştir. İkinci yıl yaş kök verimi arasında önemli farklılıklar varken kök kuru madde oranı arasında fark olmamıştır. Bunun sebebi en yüksek yaş kök verimine sahip olan çeşitlerin kök kuru madde oranı en düşük seviyede yer alırken, en düşük verime sahip olan çeşitlerinde en yüksek kuru madde oranına sahip olmalarından kaynaklanmıştır.

İlk yıla göre ikinci yıl bütün çeşitlerde yaş yaprak ağırlığı, yaş yaprak verimi ve yaş kök gövde ağırlığı daha fazla olmuştur. İkinci yıl büyüme mevsiminde daha fazla yağış düşmüştür. Özellikle haziran ayında ilk yıl hiç yağış düşmezken, ikinci yıl $25.6 \mathrm{~mm}$ yağış alınmıştır. Mayıs, temmuz ve ağustos aylarında da daha fazla yağış olmuştur. Yağışlar sulama yapılsa bile verim artışına neden olmaktadır. Bu çalışmada da ikinci yıl verimin daha yüksek çıkmasına neden olmuş olabilir. Fakat 2004 yılında bütün özellikler yüksek çıkarken yaş kök gövde verimi daha düşük çıkmıştır. Yemlik pancar toprağı besin elementleri bakımından çok sömürdüğü için ikinci yıl deneme ilk yılkinin hemen yan tarafına ekilmiştir. Fakat tüm parseller hasat edildiğinde Eckdorot çeşidi hariç diğer çeşitlerde homojen bir kök gövde gelişmesinin olmadığı belirlenmiştir. Bu nedenle dekara kök veriminin daha düşük çıkmasına neden olabilir.

Fakat yaş kök ağırlığında çeşitler arasında önemli fark olmazken, yaş kök verimlerinde önemli farklılık ortaya çıkmıştır. Bu farklılık Eckdorot çeşidinin tüm parselde kök-gövdelerinin homojen olarak gelişmesi sonucunda verimleri yüksek çıkmış olabilir. İzmir ekolojik şartlarında Geren ve Avcıoğlu (1997) Rota çeşidinin kök-gövde verimini $2473 \mathrm{~kg} / \mathrm{da}$, yine aynı bölgede Tayşi ve Demir (1979)'in yaptıkları çalışmada kök-gövde verimi 2300-4700 kg/da arasında değişmiştir. Çukurova şartlarında Sağlamtimur ve Tansı (1989) 4602.21 kg/da kök-gövde verimi bulmuşlardır. Acar (2000) Konya'da Petra çeşidinde kök gövde verimini $14514.8 \mathrm{~kg} / \mathrm{da}$ olarak bulmuştur. Karadeniz sahil kuşağında Albayrak ve Çamaş (2005) Ecdogelb çeşidinde ortalama kök-gövde verimi 9325 $\mathrm{kg} / \mathrm{da}$, Ecdorot çeşidinde ise $10356 \mathrm{~kg} / \mathrm{da}$ olarak belirlemişlerdir. Harran ovasında ise Açanal (1999) ortalama kök-gövde verimini $3301 \mathrm{~kg} / \mathrm{da}$ olarak tespit etmişlerdir. Abdel-Aal ve ark. (1990) Mısır'da hayvan pancarında kök-gövde verimini 4907 kg/da olarak belirlemişlerdir.

\section{Sonuç}

Denemede kullanılan yemlik pancarın Rota, Eckdorot, Eckdogella, Hat1 ve Hat2 çeşitleri arasında incelenen bazı verim özelliklerinde önemli bir fark ortaya çıkmamıştır. Sadece yaş kök-gövde veriminde 
fark olmuş fakat kök-gövde kuru madde veriminde herhangi bir farklılık saptanamamıştır. Araştırmada kullanılan beş çeşidin Ankara ve benzer ekolojik koşullarda yetiştiriciliği yapılabilir. Çeşitlerin kolay temini ve fiyat durumuna göre herhangi biri tercih edilebilir.

\section{Kaynaklar}

Abdel-Aal, S.H., M.S.Ibrahim and M.S.El Hardun. 1990. Effect of population Density on the growth, yield and nutritive values of some fodder beet varieties. Annals of Agricultural Science, Moshtohor. Faculty of Agriculture, Moshtohor Zagazig Üniv. 28 (2): 793-803.

Acar, R. 2000. Bazı yemlik pancar (Beta vulgaris L. rapacea Koch.) çeşitlerinde farklı ekim zamanı ve bitki sıklıkları uygulamalarının verim, verim unsurları ve kalite üzerine etkileri. Selçuk Üniv. Fen Bil. Enst. Tarla Bitkileri Ana Bilim Dalı, Doktora Tezi, 173 s.

Açanal, M. 1999. Harran ovası koşullarında farklı ekim zamanlarının hayvan pancarında (Beta vulgaris var. rapacea Koch) verime etkisinin saptanması. Harran Üniv. Fen Bil. Enst. Tarla Bitkileri Ana Bilim Dalı, Yüksek Lisans Tezi, $49 \mathrm{~s}$.

Albayrak, S. and N.Çamaş. 2005. Influence of row spacing on root yield and yield components of fodder beet (Beta vulgaris var. crassa Mansf.) in the Black Sea Coastal Region. Tarım Bilimleri Dergisi. 11 (2): 160-164.

Albayrak, S. ve N.Çamaş. 2006. Yield components of fodder beet (Beta vulgaris var. crassa Mansf.) under the Middle Black Sea region conditions. Tarım Bilimler Dergisi. 12 (1): 65-69.

Avcıoğlu, R.,H.Geren, Y.Elmalı ve O.Erkul. 1999. Farklı ekim zamanı ve sıklığının hayvan pancarı (Beta vulgaris var. rapacea Koch)'nda verim ve diğer bazı özelliklere etkisi üzerinde araștırmalar. Türkiye 3. Tarla Bitkileri Kongresi: 113-118. 15-18 Kasım 1999, Adana.

Birkenmaier, F., F.J. Schwarz, H.L.Muller and M.Kirchgessner. 1996. Feed intake and milk performance of dairy cows fed fodder beets together with grass silage. Archives of Animal Nutrition-Archiv Fur Tierernahrung 49 (4): 335-347.

Çetin, Y. ve R. Özhan.1992. Hayvan pancarı ıslahı. Mandacılık Araştırma Enstitüsü Müdürlüğü. T.C. Tarım ve Köy İşleri Bakanlığı. Afyon.

Düzgünes, O., T.Kesici,O.Kavuncu ve F.Gürbüz. 1987. Araştırma ve Deneme Metotları (İstatistik Metotları II). Ankara Üniv. Ziraat Fak.Yay.:1021, Ders Kitabı.
Elmalı, Y. 1998. Hayvan pancarı (Beta vulgaris var. rapacea Koch.)'nda farklı ekim zamanı ve sıklığın verim ve diğer bazı özelliklere etkisi üzerinde araştırmalar. Ege Üniv. Fen Bil. Enst. Tarla Bitkileri Ana Bilim Dalı, Doktora Tezi, 93s.

Geren, H. ve R. Avcıoğlu. 1997. Farklı ekim zamanlarııın değişik hayvan pancarı çeşitlerinin verim ve diğer bazı özelliklerine etkisi. Türkiye II. Tarla Bitkileri Kongresi: 699-701. 22-25 Eylül 1997, Samsun

Krousky, J. 1991. Sugar and fodder beet seed from the precultivated sugar-root seedling. Rostlinna Vyroba. 37 (3): 231-242.

Lee, J.S., J.H. Ahn, I.H.Jo, Z.S.Rho and B.D.Sangı. 1995. Effect of sowing date on the fresh yield of fodder beet cultivars. Journal of The Korean Society of Grassland Science. 15 (2): 140-145

Moloney, A.P. and P.O'Kiely. 1999. Rumen and blood variables in steers fed grass silage or whole-crop fodder beet silage. Animal Feed Science and Technology, 81: 221-223.

Nadaf, S.K., Y.M. İbrahim, M. Akhtar, M.G. El Haj and A.H. Al-lawati. 1998. Performance of fodder beet in Oman. Annals of Arid Zone. 37 (4):377-382.

Özen, N., A.Çakır, S.Haşimoğlu ve A.Aksoy. 1981. Yemler Ders Teksiri. Atatürk Üniv. Ziraat Fakültesi Zootekni Bölümü. Erzurum.

Sağlamtimur, T. ve V. Tansı. 1989. Çukurova'da hayvan pancarında en uygun ekim zamanının belirlenmesi üzerine bir arastırma. Çukurova Üniv. Ziraat Fak. Dergisi. 4 (1):62-75.

Skultety, M., N. Skultetyova and E. Bencova. 1991. The quality of silages made of fodder beet and straw nutrient digestibility and dry matter intake. Zivocisna Vyroba 36 (5): 397-402.

Tayşi, V. ve İ.Demir. 1979. Diploid ve poliploid yemlik pancar ıslahı. Ege Üniv. Ziraat Fak. Dergisi, Vamık Tayşi Özel Sayısı, Ege Üniv. Matbaası, Bornova, TÜBITAK Proje No: TOAG/177.51s.

\section{İletişim adresi:}

Altıngül ÖZASLAN PARLAK

Çanakkale Onsekiz Mart Üniv.

Ziraat Fak. Tarla Bitkileri Bölümü-Çanakkale

Tel:0 286 2180018/1354

E-posta:gulozaslan@yahoo.com 